\title{
Automated synthesis and PET evaluation of both enantiomers of [18F]FMISO
}

Revunov, Evgeny V.; Jørgensen, Jesper T.; Jensen, Andreas Tue Ingemann; Hansen, Anders Elias; Severin, Gregory; Kjær, Andreas; Zhuravlev, Fedor

Published in:

Nuclear Medicine and Biology

Link to article, DOI:

10.1016/j.nucmedbio.2014.12.010

Publication date:

2015

Document Version

Peer reviewed version

Link back to DTU Orbit

Citation (APA):

Revunov, E. V., Jørgensen, J. T., Jensen, A. T. I., Hansen, A. E., Severin, G., Kjær, A., \& Zhuravlev, F. (2015). Automated synthesis and PET evaluation of both enantiomers of [18F]FMISO. Nuclear Medicine and Biology, 42, 413-419. https://doi.org/10.1016/j.nucmedbio.2014.12.010

\section{General rights}

Copyright and moral rights for the publications made accessible in the public portal are retained by the authors and/or other copyright owners and it is a condition of accessing publications that users recognise and abide by the legal requirements associated with these rights.

- Users may download and print one copy of any publication from the public portal for the purpose of private study or research.

- You may not further distribute the material or use it for any profit-making activity or commercial gain

- You may freely distribute the URL identifying the publication in the public portal 


\section{Accepted Manuscript}

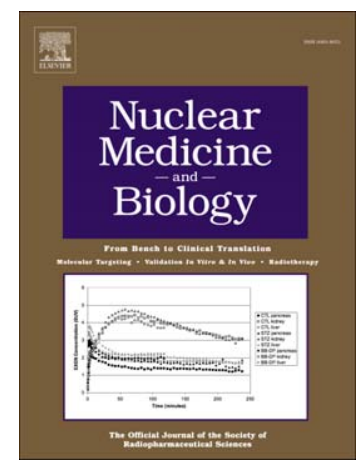

Automated synthesis and PET evaluation of both enantiomers of [ ${ }^{18}$ F]FMISO

Evgeny Revunov, Jesper T. Jørgensen, Andreas Ingemann Jensen, Anders E. Hansen, Gregory W. Severin, Andreas Kjær, Fedor Zhuravlev

PII:

S0969-8051(14)00575-7

DOI: $\quad$ doi: $10.1016 /$ j.nucmedbio.2014.12.010

Reference: $\quad$ NMB 7680

To appear in: $\quad$ Nuclear Medicine and Biology

Received date: 1 October 2014

Accepted date: 10 December 2014

Please cite this article as: Revunov Evgeny, Jørgensen Jesper T., Jensen Andreas Ingemann, Hansen Anders E., Severin Gregory W., Kjær Andreas, Zhuravlev Fedor, Automated synthesis and PET evaluation of both enantiomers of [ ${ }^{18}$ F $]$ FMISO, Nuclear Medicine and Biology (2014), doi: 10.1016/j.nucmedbio.2014.12.010

This is a PDF file of an unedited manuscript that has been accepted for publication. As a service to our customers we are providing this early version of the manuscript. The manuscript will undergo copyediting, typesetting, and review of the resulting proof before it is published in its final form. Please note that during the production process errors may be discovered which could affect the content, and all legal disclaimers that apply to the journal pertain. 


\section{Automated synthesis and PET evaluation of both enantiomers of $\left[{ }^{18} \mathrm{~F}\right] \mathrm{FMISO}$}

Evgeny Revunov $^{\text {a\# }}$, Jesper T. Jørgensen ${ }^{\text {b\# }}$, Andreas Ingemann Jensen ${ }^{\mathrm{a}}$, Anders E. Hansen ${ }^{\mathrm{b}, \mathrm{c}}$, Gregory W. Severin ${ }^{\mathrm{a}}$, Andreas $\mathrm{Kjær}^{\mathrm{b}} *$ and Fedor Zhuravlev ${ }^{\mathrm{a}} *$

${ }^{a}$ Hevesy Laboratory, DTU Nutech, Frederiksborgvej 399, Building 202, 4000 Roskilde, Denmark

${ }^{b}$ Department of Clinical Physiology, Nuclear Medicine \& PET and Cluster for Molecular Imaging, Rigshospitalet and University of Copenhagen, Blegdamsvej 3, 2200 Copenhagen, Denmark

${ }^{c}$ Department of Micro- and Nanotechnology, Center for Nanomedicine and Theranostics, DTU, 2800 Lyngby, Denmark

Article history:

Received

Received in revised form

Accepted

Available online

Keywords:

$\left[{ }^{18} \mathrm{~F}\right] \mathrm{FMISO}$

Hypoxia

PET

$\left[{ }^{18} \mathrm{~F}\right] \mathrm{HF}$

Radiofluorination

${ }^{\#}$ E. Revunov and J. T. Jørgensen contributed equally

* Corresponding authors at: Fedor Zhuravlev, Hevesy Laboratory, DTU Nutech, Frederiksborgvej 399, Building 202, 4000 Roskilde, Denmark, Tel.: +45 4677-5337; fax: +45 4677-5347; e-mail: fezh@ dtu.dk, and Andreas Kjær, Department of Clinical Physiology, Nuclear Medicine \& PET, Righospitalet, 2100 Copenhagen, Denmark, Tel.: +45 454012; fax: +4535454015; email: akjaer@ sund.ku.dk 


\section{ABSTRACT}

Introduction: $\left[{ }^{18} \mathrm{~F}\right] \mathrm{FMISO}$, the widely used positron emission tomography (PET) hypoxia tracer, is a chiral compound clinically used as a racemic mixture. The purpose of this study was to synthesize the individual (R)- and the (S)- enantiomers of $\left[{ }^{18} \mathrm{~F}\right] \mathrm{FMISO}$ and compare their PET imaging characteristics.

Methods: The radiosynthesis of enantiopure (R)- and $\left(\mathrm{S}\left[{ }^{18} \mathrm{~F}\right] \mathrm{FMISO}\right.$ was based on Co(salen) (N,N'-bis $(3,5-$ di-tert-butylsalicylidene)-1,2-cyclohexanediaminocobalt)-mediated opening of enantiopure epoxides with $\left[{ }^{18} \mathrm{~F}\right] \mathrm{HF}$. The uptake and clearance of the individual $\left[{ }^{18} \mathrm{~F}\right] \mathrm{FMISO}$ antipodes were investigated using micro-PET/CT imaging performed on mice bearing FaDu tumors. Image-derived biodistribution was obtained from micro-PET/CT scans performed at 1 and 3 hours post injection (p.i.). In addition, the uptake patterns of each enantiomer were observed using two-hour dynamic micro-PET/CT scans and the time-activity curves from different organs were compared.

Results: The individual (R)- and (S)-[ $\left[{ }^{18} \mathrm{~F}\right] \mathrm{FMISO}$ enantiomers were synthesized in one step with high enantiomeric excess (ee) $>99 \%$ and radiochemical purity $>97 \%$ using custom-made automation module. The dynamic micro-PET/CT scanning revealed a faster initial uptake of the (R)- $\left[{ }^{18} \mathrm{~F}\right] \mathrm{FMISO}$ enantiomer in tumor and muscle tissues, however the difference became progressively smaller with time. The tumor-to-muscle $(T / M)$ and tumor-to-liver $(T / L)$ ratios remained nearly identical for the (R)and (S)-forms at all time points. The micro-PET/CT imaging at 1 and 3 hours p.i. did not show any significant enantioselective tissue uptake.

Conclusions: Although the (R)-enantiomer of $\left[{ }^{18} \mathrm{~F}\right] \mathrm{FMISO}$ demonstrated a somewhat faster initial tumor and muscle uptake no significant enantioselective tissue uptake was observed at later time points. The $\mathrm{T} / \mathrm{M}$ - and $\mathrm{T} / \mathrm{L}$ - ratios for the (R)- and (S)-forms were the same within the experimental error at all times. Therefore, the use of enantiopure $\left[{ }^{18} \mathrm{~F}\right] \mathrm{FMISO}$ is unlikely to present any practical clinical benefit for PET imaging.

\section{Introduction}

Inefficient angiogenesis during growth of solid tumors often leads to spatial and temporal deficiency in their oxygen supply. When the partial pressure of oxygen decreases significantly a condition of oxygen starvation, or hypoxia, occurs. Tumor cells respond to hypoxia by activating several isoforms of hypoxia inducible factor HIF [1], which, together with various microRNAs [2] regulate gene expression responsible for glycolysis, apoptosis, DNA repair, and angiogenesis in tumor cells. As a consequence, hypoxia increases tumor cell invasion [3], activates autophagy [4] and promotes tumor motility [5] and cell pluripotency [6]. Importantly, hypoxia often increases resistance of cancer cells to chemotherapy and radiotherapy [7]. In clinical settings, the determination of hypoxia status could provide important information to stratify patients to optimize treatment, including hypoxic radiosensitizers and hypoxia guided radiation therapy. Presently, a number of methods for detection and measuring tumor hypoxia are available, such as the Eppendorf needle electrode, immunostaining, fluorescence and diffuse reflectance spectroscopy [8]. In the 1980s, positron emission tomography (PET) emerged as a noninvasive, viable-cell specific, highly sensitive quantitative hypoxia accessing modality. Subsequently, a 
series of 2-nitro-imidazoles labeled with fluorine-18 in a position peripheral to the imidazole ring was developed and successfully used to measure hypoxia [9]. Among these, ([ $\left.{ }^{18} \mathrm{~F}\right] 1-(2-n i t r o i m i d a z o l e-1-y)-3-$ fluoropropane-2-ol ([ ${ }^{18}$ F]FMISO) is currently the most used hypoxia PET tracer (Fig. 1).

Central to the structure-activity relationship of $\left[{ }^{18} \mathrm{~F}\right] \mathrm{FMISO}$ is a redox-active 2-nitroimidazole ring, which allows the molecule to accept terminal electrons from the respiratory cycle. In hypoxic regions, where the concentration of dioxygen is too low to re-oxidize the initially formed - $\mathrm{NO} 2_{-}^{-}$, the anion radical undergoes further reduction to $-\mathrm{NH} 2$, and the resulting species binds covalently to the macromolecules.

$\left[{ }^{18} \mathrm{~F}\right] \mathrm{FMISO}$ is a chiral compound, which is currently used as a racemic mixture in PET. It is well known that chirality may affect the affinity and/or efficacy of drugs [10], and different enantiomers may display different pharmacokinetic profiles [11]. Several factors may cause such differences. In particular, binding to tissue and plasma proteins, primarily to albumin, as well as to lipoproteins and red blood cells can be stereoselective [11,12]. As this binding affects the plasma concentration of free drug, this could in turn affect the rates of excretion and degradation and ultimately plasma half-life and biodistribution. In addition, active renal excretion and reabsorption, as well as enzymatic drug metabolism [11] have been shown to be stereoselective in certain cases $[11,13]$. Therefore, it is generally important to determine if different enantiomers of a drug have different in vivo efficacy based on stereoselective pharmacokinetics. Further, in the special case of $\left[{ }^{18} \mathrm{~F}\right] \mathrm{FMISO}$, the electron transport to the 2nitroimidazole ring can be mediated by a variety of chiral macromolecules, including nitroreductase enzymes [14]. For these reasons, the question arises as to what degree the imaging characteristics of the two enantiomers of $\left[{ }^{18} \mathrm{~F}\right] \mathrm{FMISO}$ differ. In the field of nuclear medicine, this is particularly important, as the use of the more active enantiomer could potentially decrease the amount of administered radioactivity, and thus the dose to the patient. In addition, if one enantiomer is more specific, the use of this enantiomer could enhance image quality. Herein, we report an enantiospecific, single-step radiosynthesis of both enantiomers of $\left[{ }^{18} \mathrm{~F}\right] \mathrm{FMISO}$. The biodistribution and imaging abilities of (S)-and (R)- $\left[{ }^{18} \mathrm{~F}\right] \mathrm{FMISO}$ were evaluated by PET in FaDu tumor xenograft bearing mice.

\section{Materials and methods}

\subsection{General}

Chemicals were purchased from Sigma-Aldrich and $A B X \mathrm{GmbH}$ and used without further purification unless stated otherwise. 1,1,1,3,3,3-Hexafluoro-2-propanol (HFIP) was purified by sequential passing through silica, and activated alumina followed by vacuum distillation. Acetonitrile (ACN), ethyl acetate

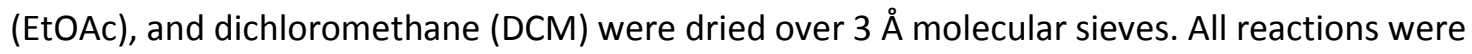
performed without exclusion of moisture and air. The silica cartridges (Supelco, $4 \mathrm{~g}$ ) were preconditioned with hexane. The HPLC and radio-HPLC measurements were performed on a Hitachi EliteChrom equipped with Carrol \& Ramsey 105-S radiodetector. The normal phase chiral HPLC/radioHPLC was done with a Chiralpak AD-3, $150 \times 2.1 \mathrm{~mm}$ column using hexane/i-PrOH (10:1) isocratic 
elution. The GC was performed on a Shimadzu GC-2010 equipped with FactorFour calillary column, VF$200 \mathrm{~ms}, 30 \mathrm{~m}, 0.32 \mathrm{~mm}$. The aqueous solutions of $\left[{ }^{18} \mathrm{~F}\right] \mathrm{fluoride}$ were prepared by the $180(p, n){ }^{18} \mathrm{~F}$ reaction in a GE PETtrace cyclotron by irradiating 95\% enriched [180]water ( $2 \mathrm{~mL})$ with the nominal 16.5 $\mathrm{MeV}$ beam at $55 \mu \mathrm{A}$ for $60-90 \mathrm{~min}$. The decay corrected preparative radiochemical yields (RCYs) of both enantiomers of $\left[{ }^{18} \mathrm{~F}\right] \mathrm{F}$-MISO were determined on the cartridge-purified sterile saline formulation of the product relative to $\left[{ }^{18} \mathrm{~F}\right]$ fluoride. The radiochemical purity (RCP) was determined by radio-HPLC and calculated as: $\mathrm{RCP}=\left(\right.$ Area $_{\text {product }} /$ Total Area $) * 100 \%$.

\subsection{Chemistry}

\subsubsection{Starting materials and references}

The reference racemic FMISO was purchased from $A B X \mathrm{GmbH}$. The reference enantiopure FMISO (both enantiomers) were prepared according to the reported procedure [15]. (R)- and (S)-2-nitro-1-(oxiran-2ylmethyl)-1H-imidazoles, the ((R) and (S)-MISO-epoxides) were synthesized similarly to the previously described protocol [16]: a stirred suspension of 2-nitroimidazole (1.00 g, $8.84 \mathrm{mmol}, 1.0 \mathrm{eq}$ ) and cesium carbonate (145 mg, $0.44 \mathrm{mmol}, 0.05$ eq.) in dry ethanol $(20 \mathrm{~mL})$ was treated with the (R)- or the (S)epichlorohydrin ( $760 \mu \mathrm{L}, 9.60 \mathrm{mmol}, 1.1$ eq.), and the resulting mixture was refluxed for $1 \mathrm{~h}$ under argon. The hot solution was filtered through glass wool; solids were washed with hot ethanol (10 $\mathrm{mL})$. The reaction mixture was concentrated in vacuo and cooled to $-20^{\circ} \mathrm{C}$. The resulting off-white precipitate of 1-(2-hydroxy-3-chloropropyl)-2-nitroimidazole was dissolved in $20 \mathrm{~mL}$ of EtOAc and treated with aqueous $\mathrm{NaOH}(10 \%(\mathrm{w} / \mathrm{v}), 20 \mathrm{~mL})$. After stirring for $1 \mathrm{~h}$ the organic layer was separated, dried over $\mathrm{Na}_{2} \mathrm{SO}_{4}$ giving after solvent removal $1.31 \mathrm{~g}(88 \%)$ of (S)-MISO-epoxide or $1.26 \mathrm{~g}(85 \%)$ of (R)-MISOepoxide.

\subsubsection{Automated radiosynthesis, purification of (R)-and (S)-MISO, and quality control.}

$\left[{ }^{18} \mathrm{~F}\right] \mathrm{HF}$ (gas) was generated by addition of $\sim 2 \mathrm{~mL}$ of proton-irradiated [180]H2O containing $70-95 \mathrm{GBq}$ of $\left[{ }^{18} \mathrm{~F}\right]$ fluoride into a polyehtylene vial containing conc. $\mathrm{H} 2 \mathrm{SO} 4(8 \mathrm{~mL})$. Upon heating to $85^{\circ} \mathrm{C}$ and ultrasound irradiation the gaseous $\left[{ }^{18} \mathrm{~F}\right] \mathrm{HF}$ was driven by argon flow into a receiving vial containing 3.5 $\mathrm{mg}$ of (-)tetramisol in $3 \mathrm{~mL}$ of t-AmOH. Upon completion of the $\left[{ }^{18} \mathrm{~F}\right] \mathrm{HF}$ transfer ( $\left.30 \mathrm{~min}\right), 1.5 \mathrm{~mL}$ of the $\left[{ }^{18} \mathrm{~F}\right] \mathrm{HF} /(-)$ tetramisol mixture was transferred into a glass reaction vial containing a solution of $5 \mathrm{mg}$ of (R)- or (S)-MISO-epoxides and $4.5 \mathrm{mg}$ of (R,R)-Co(salen) ((N,N'-bis(3,5-di-tert-butylsalicylidene)-1,2cyclohexanediaminocobalt)) pre-oxidized in air in the presence of $250 \mu \mathrm{L}$ of HFIP. The reaction mixture was heated at $65 \mathrm{oC}$ for $15 \mathrm{~min}$ and then transferred onto a silica cartridge preconditioned with hexane. The product was purified by sequential elution with hexane $(20 \mathrm{~mL}), \mathrm{DCM}(20 \mathrm{~mL})$ and then DCM/ACN $(3: 1,20 \mathrm{~mL})$. The organic solvent was removed under elevated temperature by applying vacuum (diaphragm pump) and a flow of $\operatorname{Ar}(40 \mathrm{~mL} / \mathrm{min})$. The dry product was dissolved in $3 \mathrm{~mL}$ of phosphate buffered saline (PBS, $3 \mathrm{~mL}$ ) and filtered through a sterile filter, giving $628 \mathrm{MBq}(\mathrm{RCY}=2 \%)$ of the $(\mathrm{R})$ $\left[{ }^{18} \mathrm{~F}\right] \mathrm{FMISO}$ and $2.97 \mathrm{GBq}$ of $(\mathrm{S})-\left[{ }^{18} \mathrm{~F}\right] \mathrm{FMISO}(\mathrm{RCY}=7 \%)$ at the end of the synthesis which took 2 hours. The 
$\mathrm{pH}$ was measured using $\mathrm{pH}$ paper and the residual organic solvent test was performed using $\mathrm{GC}$. The specific activity was estimated from a 5-point calibration curve using UV-VIS spectroscopy and found to exceed $100 \mathrm{GBq} / \mu \mathrm{mol}$.

\subsubsection{Animals and cell lines}

All included animal experiments were approved by the Danish Animal Welfare Council, Ministry of Justice. Five week old female NMRI nude mice were purchased from Taconic Europe. Throughout the experiments the animals had ad libitum access to chow and water. After the mice arrived at the animal facility they were allowed to acclimatize for one week. Human pharyngeal squamous cell carcinoma (FaDu) cells, purchased from American Type Culture Collection (ATCC), were cultured in Minimum Essential Medium (MEM) with Earle's salts and sodium bicarbonate supplemented with 2 mM Lglutamine (both from Sigma-Aldrich), $1 \mathrm{mM}$ sodium pyruvate, 1\% MEM non-essential amino acids solution (100x), 10\% fetal calf serum, 100 units $/ \mathrm{mL}$ penicillin and $100 \mu \mathrm{g} / \mathrm{mL}$ streptomycin (all from Invitrogen) at $37^{\circ} \mathrm{C}$ in $5 \% \mathrm{CO}_{2}$. Tumors were established by subcutaneous injections of $10^{6}$ cancer cells, dissolved in $100 \mu \mathrm{L}$ of a (1:1) mixture of cell culture medium and Matrixgel ${ }^{\mathrm{TM}}$ (BD-Biosciences), into each flank. Tumors were allowed to grow for two weeks reaching a size of $100-280 \mathrm{~mm}^{3}$.

\subsubsection{PET imaging}

Animals were anesthetized by breathing 3\% sevoflurane (Abbot Scandinavia) dissolved in a medical grade $35 \%$ oxygen/nitrogen gas mixture and the body temperature was kept stable by a heating pad. Mice with similar tumor sizes were evenly distributed between the two groups and had either (S)$\left[{ }^{18} \mathrm{~F}\right] \mathrm{FMISO}(4.7 \pm 1.1 \mathrm{MBq}($ mean $\pm \mathrm{SD}) ; n=5)$ or $(\mathrm{R})-\left[{ }^{18} \mathrm{~F}\right] \mathrm{FMISO}(5.1 \pm 0.5 \mathrm{MBq} ; \mathrm{n}=5)$ injected via the tail vein and were imaged at $1 \mathrm{~h}$ and $3 \mathrm{~h}$ p.i. using a microPET 120 (Siemens Medical Solutions). Ten minute static PET scans were acquired with an energy window of 350-650 keV and a time resolution of 6 ns and stored in listmode. Additionally, a group of mice were dynamically PET scanned for two hours after intravenous injection of either (S)-[ $\left.{ }^{18} \mathrm{~F}\right]$ FMISO $(8.8 \pm 1.8 \mathrm{MBq} ; \mathrm{n}=3)$ or $(\mathrm{R})-\left[{ }^{18} \mathrm{~F}\right] \mathrm{FMISO}(7.7 \pm 1.4$ $\mathrm{MBq} ; \mathrm{n}=3$ ). The PET acquisition was initiated a few seconds before tracer administration. Subsequently after each PET scan, the animal bed was moved to a MicroCAT ${ }^{\circledR}$ II system (Siemens Medical Solutions) and all mice were CT scanned with an exposure time of $270 \mathrm{~ms}$, a tube current of $500 \mu \mathrm{A}$ and a tube voltage of $70 \mathrm{kVp}$.

\subsubsection{PET data analysis}

Listmode PET data was post-processed into $128 \times 144 \times 95$ sinograms and reconstructed using the maximum a posteriori (MAP) algorithm $256 \times 256 \times 95$ image matrices with a voxel size of $0.30 \times 0.30 \times$ 0.80 and a resolution of $1.2 \mathrm{~mm}$ at the center field of view. Dynamic PET data was binned into timeframes of $20 \times 3 \mathrm{~s} ; 12 \times 5 \mathrm{~s} ; 6 \times 30 \mathrm{~s} ; 10 \times 60 \mathrm{~s} ; 7 \times 900 \mathrm{~s}$. CT scans were reconstructed into $512 \times$ 
$512 \times 768$ image matrices with a voxel size of $0.09 \times 0.09 \times 0.09$ using the Sheep-Logan algorithm. Image data were analyzed using Inveon software (Siemens Medical Solutions). PET and CT images were coregistered and visually inspected. Regions of interest (ROIs) were manually created on tumors and sections of liver, heart, bladder, kidney and hind limb muscle tissue and the uptake quantified as percent of injected dose per gram (\%ID/g). An average value from ROIs created on both left and right side on the animal was calculated for kidney and muscle uptake. Using the same setup time activity curves were generated from the dynamic datasets and the average uptake in the quantified tissue determined. Additionally, the tumor-to-muscle (T/M) and tumor-to-liver (T/L) ratios were calculated for all animals.

\subsection{Statistical analysis}

All statistical analyses were performed in GraphPad Prism 6 (GraphPad Software). The uptake of (S)$\left[{ }^{18} \mathrm{~F}\right] \mathrm{FMISO}$ and $(\mathrm{R})-\left[{ }^{18} \mathrm{~F}\right] \mathrm{FMISO}$ was compared in different tissue using unpaired t-test with correction for multiple comparison using the Holm-Sidak method. Differences were considered significant at the $95 \%$ confidence level $(p<0.05)$.

\section{Results and discussion}

\subsection{Automated radiosynthesis of (R)- and (S)- $\left[{ }^{18}\right.$ F]FMISO and quality control.}

To the best of our knowledge the only synthesis of both enantiopure FMISO antipodes was performed with fluorine-19 at natural abundance level [17]. Our approach to radiosynthesis of enantiopure (R)- and (S)- $\left[{ }^{18} \mathrm{~F}\right] \mathrm{FMISO}$ was based on a recently disclosed transition metal mediated enantioselective epoxide opening which utilized $\left[{ }^{18} \mathrm{~F}\right] \mathrm{HF}$ in a combination with (-)tetramisole and (R,R)-Co(salen) [18]. To maximize the enantiomeric purity of the desired (R)- and (S)- $\left[{ }^{18} \mathrm{~F}\right] \mathrm{FMISO}$ the radiosynthesis was performed on enantiopure substrates. Due to a notable cooperative effect [15] the stereochemically matched enantiomers of Co(salen) were used (Scheme 1):

The radiosynthesis was automated using a custom-made automatic synthesizer controlled by LabView software (Fig. 2).

The $\left[{ }^{18} \mathrm{~F}\right] \mathrm{HF}$ generator described by us earlier $[19,20]$ was integrated within the automatic radiosynthesis platform (Fig.2, top). After $\left[{ }^{18} \mathrm{~F}\right] \mathrm{HF}$ transfer the $\left[{ }^{18} \mathrm{~F}\right] \mathrm{HF} /(-)$ tetramisol mixture was transferred into the reaction vial containing a solution of (R)- or (S)-MISO-epoxides and (R,R)- or (S,S)Co(salen) (Fig.2, bottom). After reaction, the reaction mixture was transferred onto a silica cartridge and 
the product was purified by gradient elution. The organic solvent was removed and the dry product collected in the product vial was dissolved in PBS and filtered through a sterile filter.

The final formulation of $(\mathrm{R})$ - and $(\mathrm{S})-\left[{ }^{18} \mathrm{~F}\right] \mathrm{FMISO}$ passed the $\mathrm{pH}$ test $(\mathrm{pH}=7.0-7.5)$. The residual organic solvents (ACN and DCM) were below the limit of detection. The identity of the synthesized $\left[{ }^{18} \mathrm{~F}\right] \mathrm{FMISO}$ was confirmed by radio-HPLC and HPLC against the reference sample purchased from ABX GmbH. The HPLC analysis revealed no significant absorption at $254 \mathrm{~nm}$, and radio-HPLC showed that the radiochemical and enantiomeric purities of the $(R)$ - and the $(S)$ - enantiomers of $\left[{ }^{18} \mathrm{~F}\right] \mathrm{FMISO}$ were higher than $99 \%$ (Fig. 3).

\subsection{PET evaluation of (R)- and (S)- $\left[{ }^{18} \mathrm{~F}\right] \mathrm{FMISO}$}

Fig. 4 shows representative transverse PET images of mice bearing FaDu tumor xenografts acquired 1 and 3 hours after injection of (R)- and (S)-[ $\left.{ }^{18} \mathrm{~F}\right]$ FMISO.

Table 1 shows the PET-derived tissue uptake in different organs. Both enantiomers showed pronounced abdominal distribution dominated by renal and, to a lesser degree, hepatobiliary clearance. There was no visual variation in the contrast between the PET images acquired within the two groups. The uptake of (R)- and (S)-[ $\left.{ }^{18} \mathrm{~F}\right] \mathrm{FMISO}$ in the liver, heart, kidney, bladder and muscle tissue were the same, within the error of experiment, both 1 and 3 hours p.i. Importantly, there was no significant difference in the tumor accumulation between the two groups. Generally, the tumor uptake was between $2.0-2.5 \% \mathrm{ID} / \mathrm{g}$ 1 hour p.i. decreasing to 1.0-1.5 \%ID/g 3 hours p.i. This also resulted in compatible T/M-ratio with (R)and (S)- $\left[{ }^{18} \mathrm{~F}\right] \mathrm{FMISO}$ increasing from $1.6 \pm 0.2$ and $1.4 \pm 0.31$ hour p.i. to $3.7 \pm 0.7$ and $3.6 \pm 1.33$ hours p.i., respectively. In addition, no significant difference was seen in the T/L-ratio both 1 and 3 hours p.i. (Figure 5).

A somewhat different picture emerged from the 2 hours dynamic PET imaging (Fig. 6). When the mean time activity curves from the two enantiomers were compared, a faster uptake of the (R)-form was observed in tumor tissue. The difference got progressively smaller with time. However, a similar trend was seen in muscle and liver tissue and no difference was observed between the mean T/M- and T/Lratios of (S)- $\left[{ }^{18} \mathrm{~F}\right] \mathrm{FMISO}$ and $(\mathrm{R})-\left[{ }^{18} \mathrm{~F}\right] \mathrm{FMISO}$ during the 2 hours dynamic scan. The nature of the higher initial affinity of the $(\mathrm{R})$-isomer is unclear at the moment. 


\section{Conclusion}

In conclusion, the individual enantiopure (R)- and (S)-enantiomers of $\left[{ }^{18} \mathrm{~F}\right] \mathrm{FMISO}$ were synthesized using a novel approach based on Co(salen) mediated epoxide opening with $\left[{ }^{18} \mathrm{~F}\right] \mathrm{HF}$. The PET imaging characteristics of the (R)- and (S)-forms were compared in mice bearing subcutaneous FaDu tumor xenografts. Although the (R)-enantiomer of $\left[{ }^{18} \mathrm{~F}\right] \mathrm{FMISO}$ demonstrated a somewhat faster initial tumor, liver and muscle uptake the $T / M$ - and $T / L$ ratios for the (R)- and (S)-forms were the same at all times. Image-derived biodistribution showed no significant differences in tissue uptake for the (R)- and (S)forms 1 and 3 hours after administration. On the basis of these studies we can conclude that the use of enantiopure $\left[{ }^{18} \mathrm{~F}\right] \mathrm{FMISO}$ presents no practical clinical benefits for PET imaging.

\section{References}

[1] Loboda A, Jozkowicz A, Dulak J. HIF-1 versus HIF-2-Is one more important than the other? Vascul Pharmacol 2012;56:245-51.

[2] Nallamshetty S, Chan SY, Loscalzo J. Hypoxia: A master regulator of microRNA biogenesis and activity. Free Radic Biol Med 2013;64:20-30.

[3] Teppo S, Sundquist E, Vered M, Holappa H, Parkkisenniemi J, Rinaldi T, et al. The hypoxic tumor microenvironment regulates invasion of aggressive oral carcinoma cells. Exp Cell Res 2013;319:376-89.

[4] Hu Y-L, Jahangiri A, De Lay M, Aghi MK. Hypoxia-induced tumor cell autophagy mediates resistance to antiangiogenic therapy. Autophagy 2012;8:979-81.

[5] Leong HS, Chambers AF. Hypoxia promotes tumor cell motility via RhoA and ROCK1 signaling pathways. Proc Natl Acad Sci 2014;111:887-8.

[6] Mathieu J, Zhou W, Xing Y, Sperber H, Ferreccio A, Agoston Z, et al. Hypoxia-Inducible Factors Have Distinct and Stage-Specific Roles during Reprogramming of Human Cells to Pluripotency. Cell Stem Cell 2014;14:592-605.

[7] Wilson WR, Hay MP. Targeting hypoxia in cancer therapy. Nat Rev Cancer 2011;11:393-410.

[8] Chitneni SK, Palmer GM, Zalutsky MR, Dewhirst MW. Molecular Imaging of Hypoxia. J Nucl Med 2011;52:165-8.

[9] Wuest M, Wuest F. Positron emission tomography radiotracers for imaging hypoxia. J Label Compd Radiopharm 2013;56:244-50.

[10] McConathy J, Owens MJ. Stereochemistry in drug action. Prim Care Companion J Clin Psychiatry 2003;5:70.

[11] Brocks DR. Drug disposition in three dimensions: an update on stereoselectivity in pharmacokinetics. Biopharm Drug Dispos 2006;27:387-406.

[12] Shen Q, Wang L, Zhou H, Jiang H, Yu L, Zeng S. Stereoselective binding of chiral drugs to plasma proteins. Acta Pharmacol Sin 2013;34:998-1006.

[13] Dong H, Guo X, Li Z. Pharmacokinetics of chiral drugs. Chiral Drugs Chem Biol Action 2011:347-79.

[14] Prekeges J, Rasey J, Grunbaum Z, Krohn K. Reduction of fluoromisonidazole, a new imaging agent for hypoxia. Biochem Pharmacol 1991;42:2387-95.

[15] Kalow JA, Doyle AG. Mechanistic Investigations of Cooperative Catalysis in the Enantioselective Fluorination of Epoxides. J Am Chem Soc 2011;133:16001-12.

[16] Sercel AD, Beylin VG, Marlatt ME, Leja B, Showalter HD, Michel A. Synthesis of the enantiomers of the dual function 2-nitroimidazole radiation sensitizer RB 6145. J Heterocycl Chem 2006;43:1597-604.

[17] Borzęcka W, Lavandera I, Gotor V. Biocatalyzed synthesis of both enantiopure fluoromisonidazole antipodes. Tetrahedron Lett 2013;54:5022-5.

[18] Revunov E, Zhuravlev F. Co(salen)-mediated enantioselective radiofluorination of epoxides. Radiosynthesis of enantiomerically enriched $\left[{ }^{18}\right.$ F]F-MISO via kinetic resolution. J Fluor Chem 2013;156:130-5.

[19] Mathiessen B, Jensen M, Zhuravlev F. $\left[{ }^{18} \mathrm{~F}\right]$ Fluoride recovery via gaseous $\left[{ }^{18} \mathrm{~F}\right] \mathrm{HF}$. J Label Compd Radiopharm 2011;54:816-8.

[20] Mathiessen B, Jensen ATI, Zhuravlev F. Homogeneous Nucleophilic Radiofluorination and Fluorination with Phosphazene Hydrofluorides. Chem - Eur J 2011;17:7796-805. 


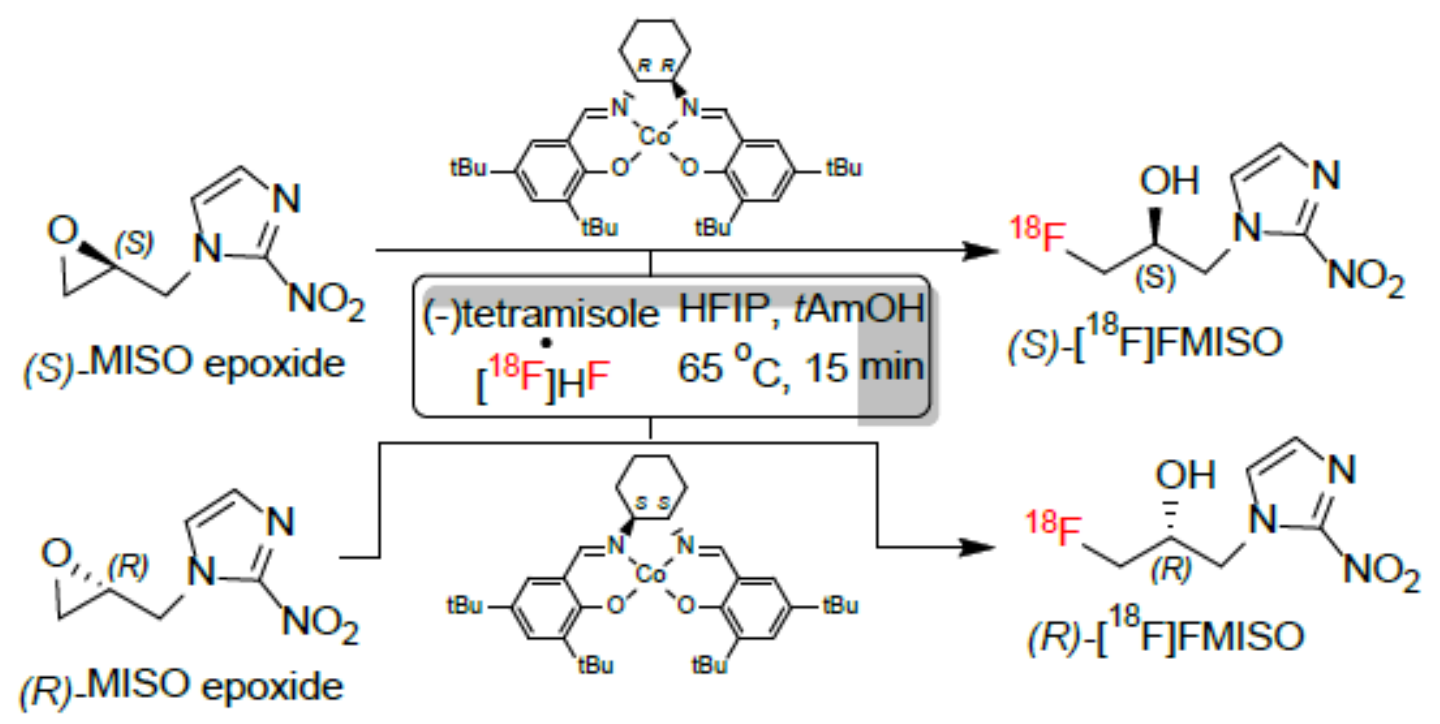

Scheme 1. Radiosynthesis of (R)- and (S)- enantiomers of $\left[{ }^{18} \mathrm{~F}\right] \mathrm{FMISO}$. 


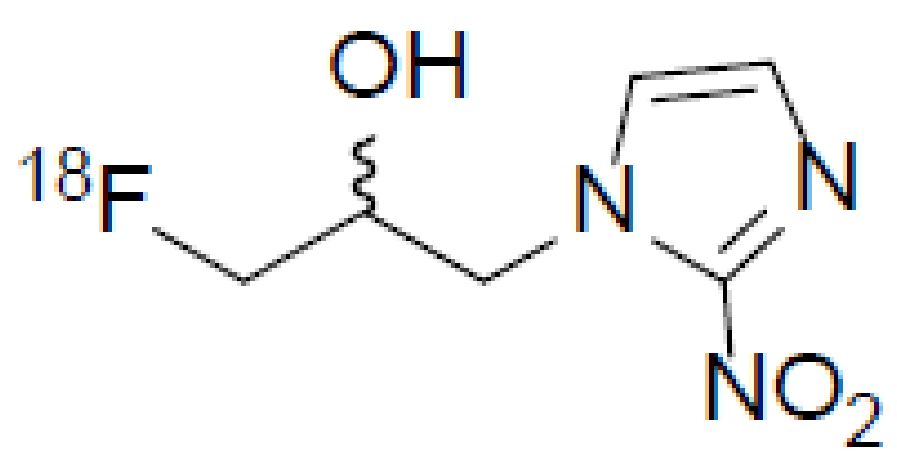

Fig. 1. Racemic $\left[{ }^{18} \mathrm{~F}\right] \mathrm{FMISO}$. 


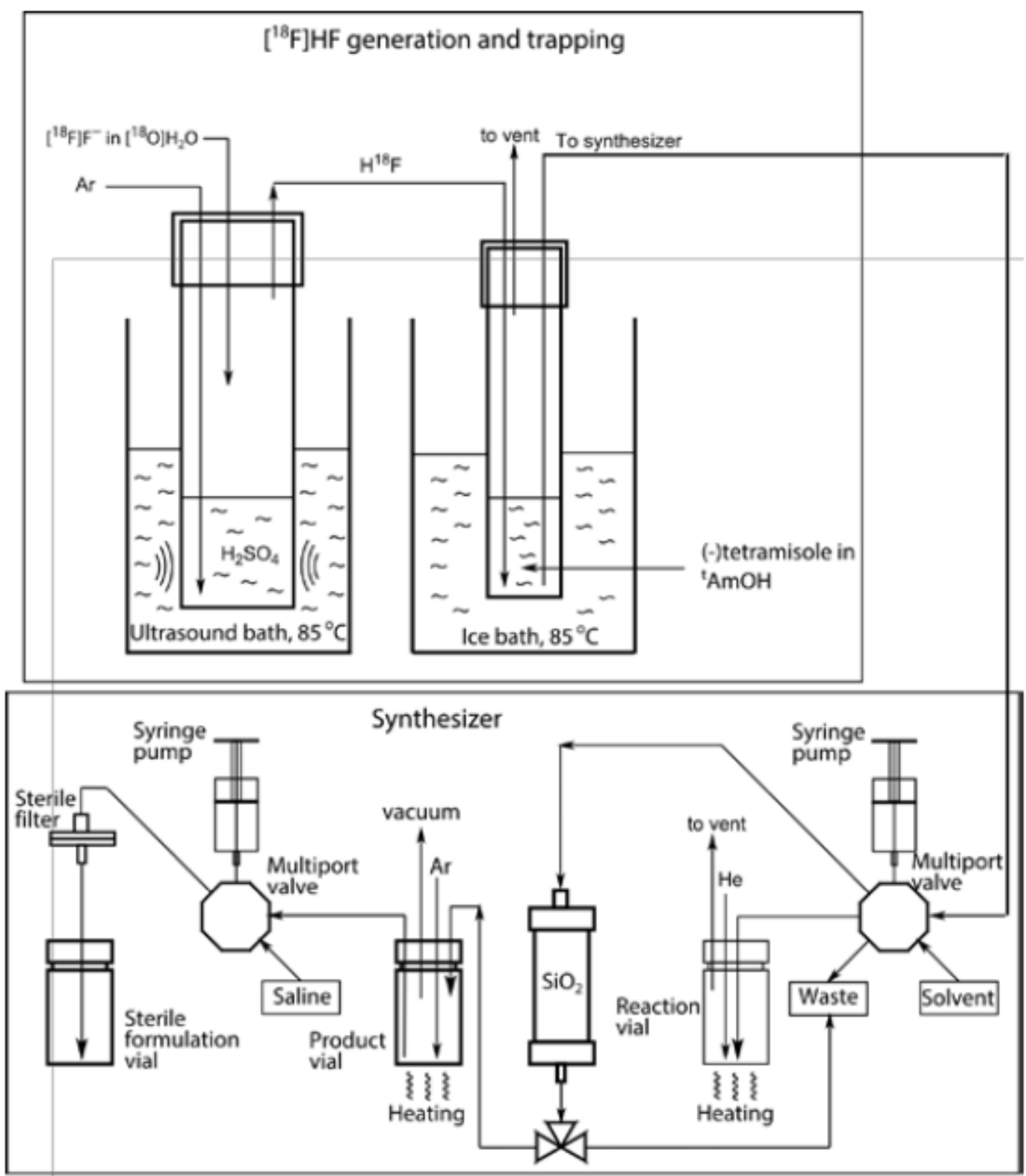

Fig. 2. Automated module for Co(salen)-mediated radiosynthesis of (R)-and (S)- enantiomers of $\left[{ }^{18} \mathrm{~F}\right] \mathrm{FMISO}$ using $\left[{ }^{18} \mathrm{~F}\right] \mathrm{HF} /(-)$ tetramisol. 


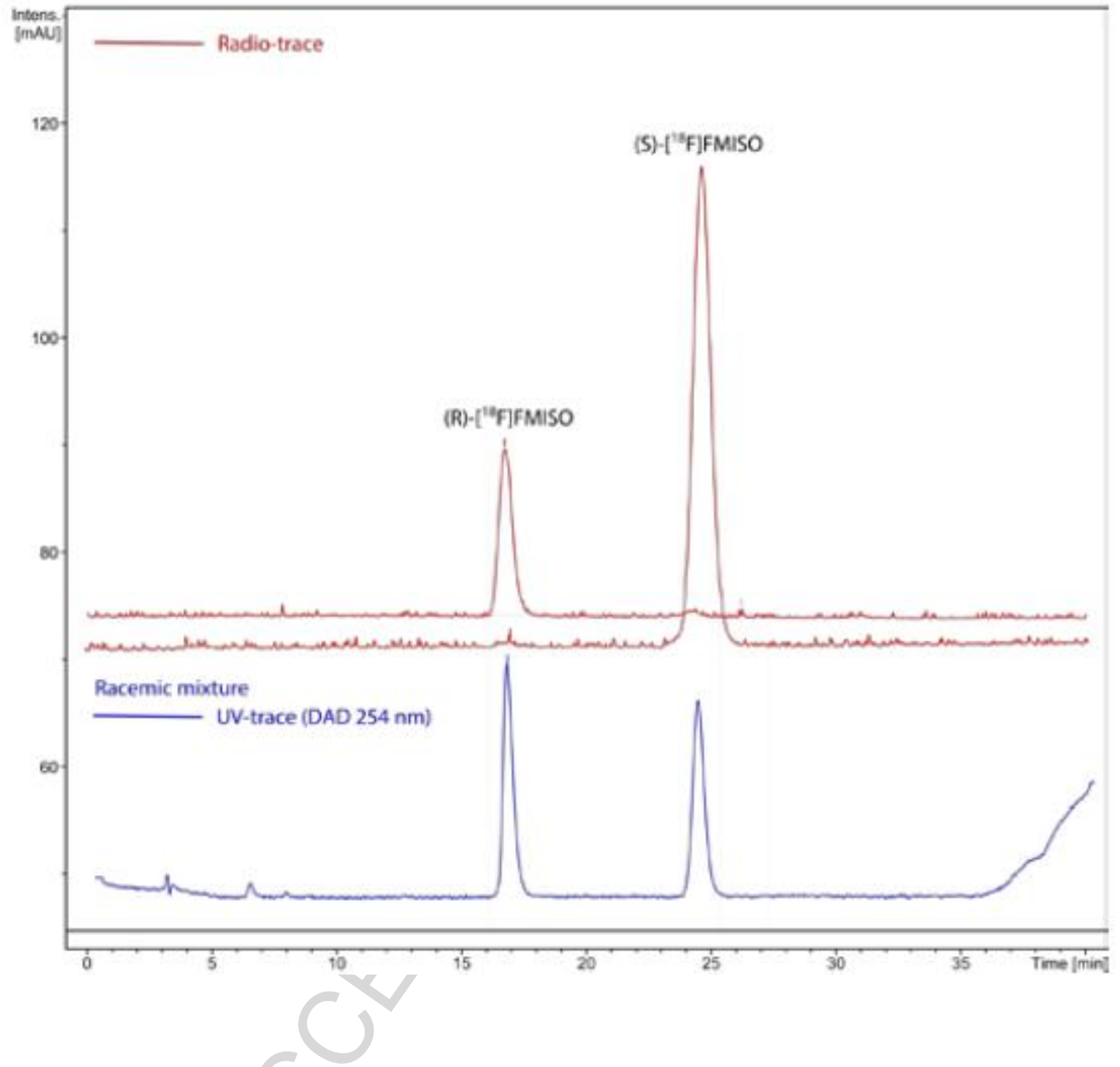

Fig. 3. Chiral radio-HPLC (top, red, arbitrary units) traces of the final formulation of (R)- and (S)[18F]FMISO, and HPLC (DAD $254 \mathrm{~nm}$ ) trace of a racemic commercial reference of $\left[{ }^{18} \mathrm{~F}\right] \mathrm{FMISO}$ obtained from $A B X \mathrm{GmbH}$. 


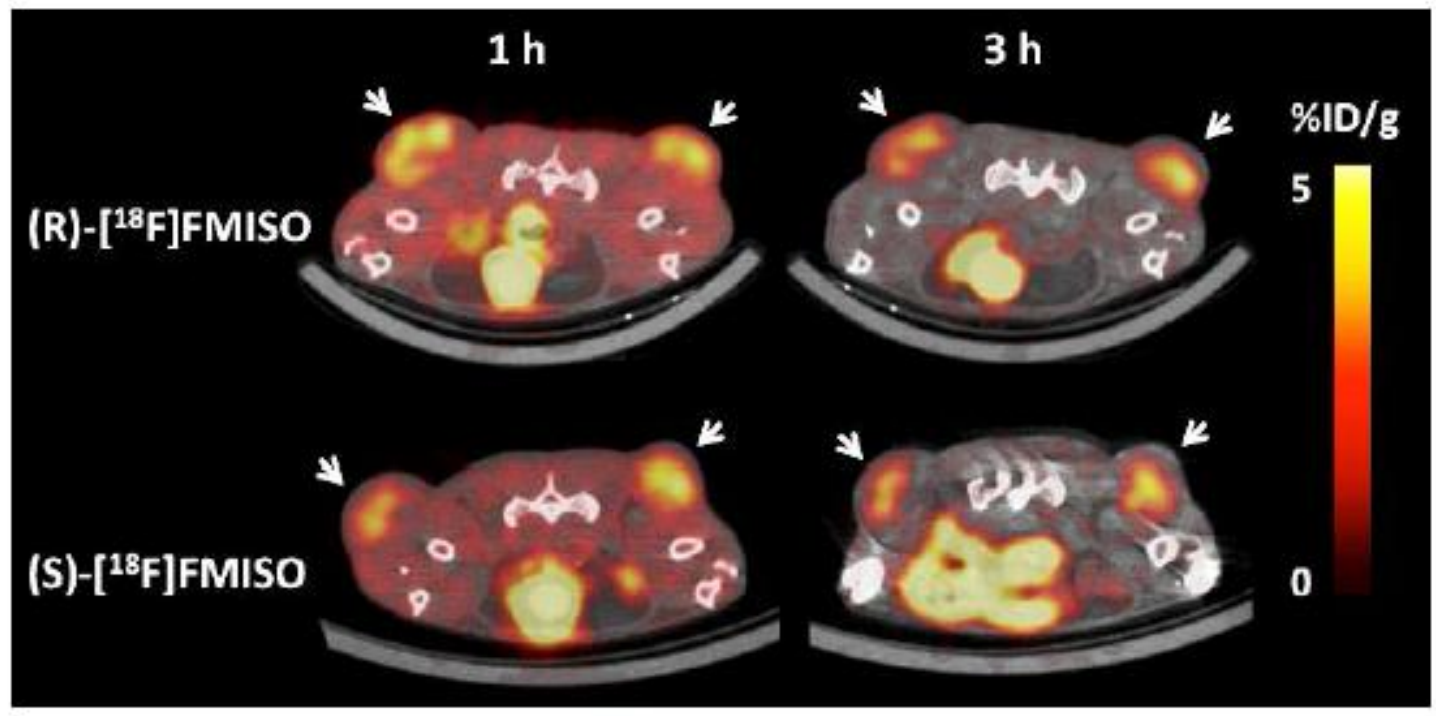

Fig. 4. Representative transverse images obtained from $10 \mathrm{~min}$ static PET scans of tumor-bearing mice acquired $1 \mathrm{~h}$ (left) and $3 \mathrm{~h}$ (right) after administration of (R)- $\left[{ }^{18} \mathrm{~F}\right] \mathrm{FMISO}$ (5.17 MBq; top lane) and (S)$\left[{ }^{18} \mathrm{~F}\right] \mathrm{FMISO}$ (4.38 MBq; bottom lane). White arrows indicate tumors. 


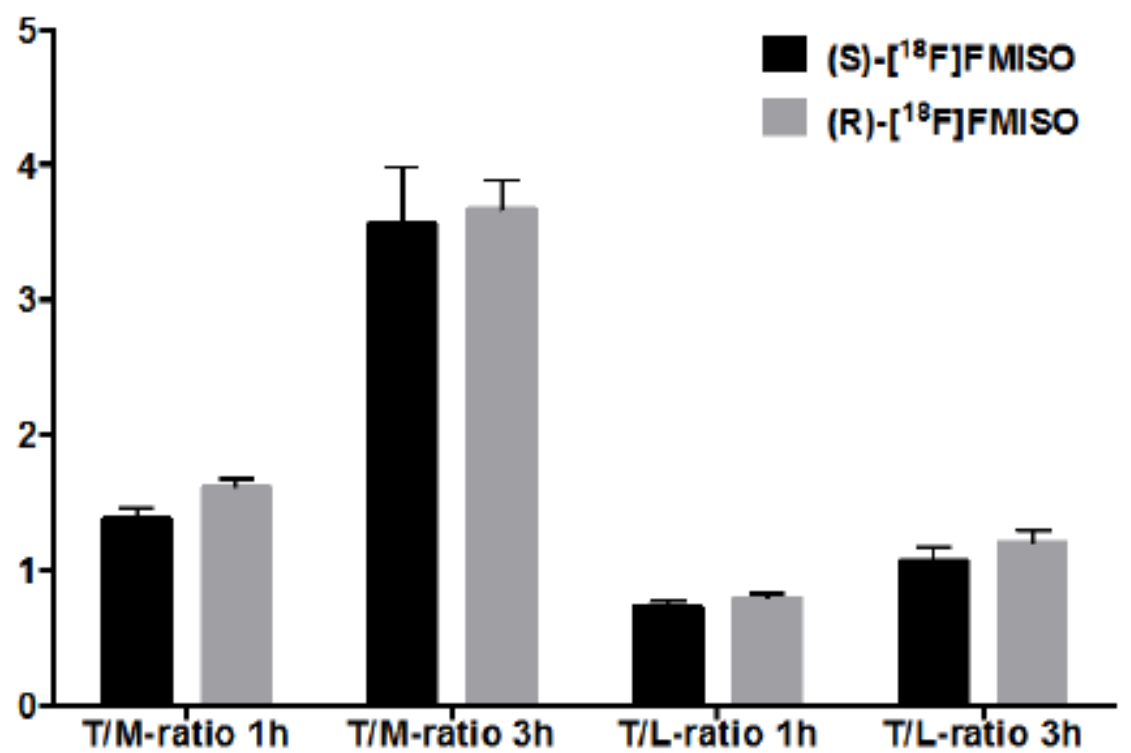

Fig. 5. Tumor-to-muscle and tumor-to-liver ratio (mean $\pm S E M$ ) from PET images of mice with FaDu tumor xenografts PET scanned $1 \mathrm{~h}$ and $3 \mathrm{~h}$ p.i. of $(\mathrm{R})-\left[{ }^{18} \mathrm{~F}\right] \mathrm{FMISO}(5.1 \pm 0.5 \mathrm{MBq}$ (mean $\pm \mathrm{SEM}) ; \mathrm{n}=5$ ) or (S)- $\left[{ }^{18} \mathrm{~F}\right] \mathrm{FMISO}(4.7 \pm 1.1 \mathrm{MBq} ; \mathrm{n}=5)$. During PET scans mice were anesthetized by breathing $3 \%$ of sevoflurane dissolved in a gas mixture of $35 \%$ oxygen in nitrogen No significant differences in T/M- or T/L-ratios were found between the enantiomers at any time point $(p<$ 0.05). 

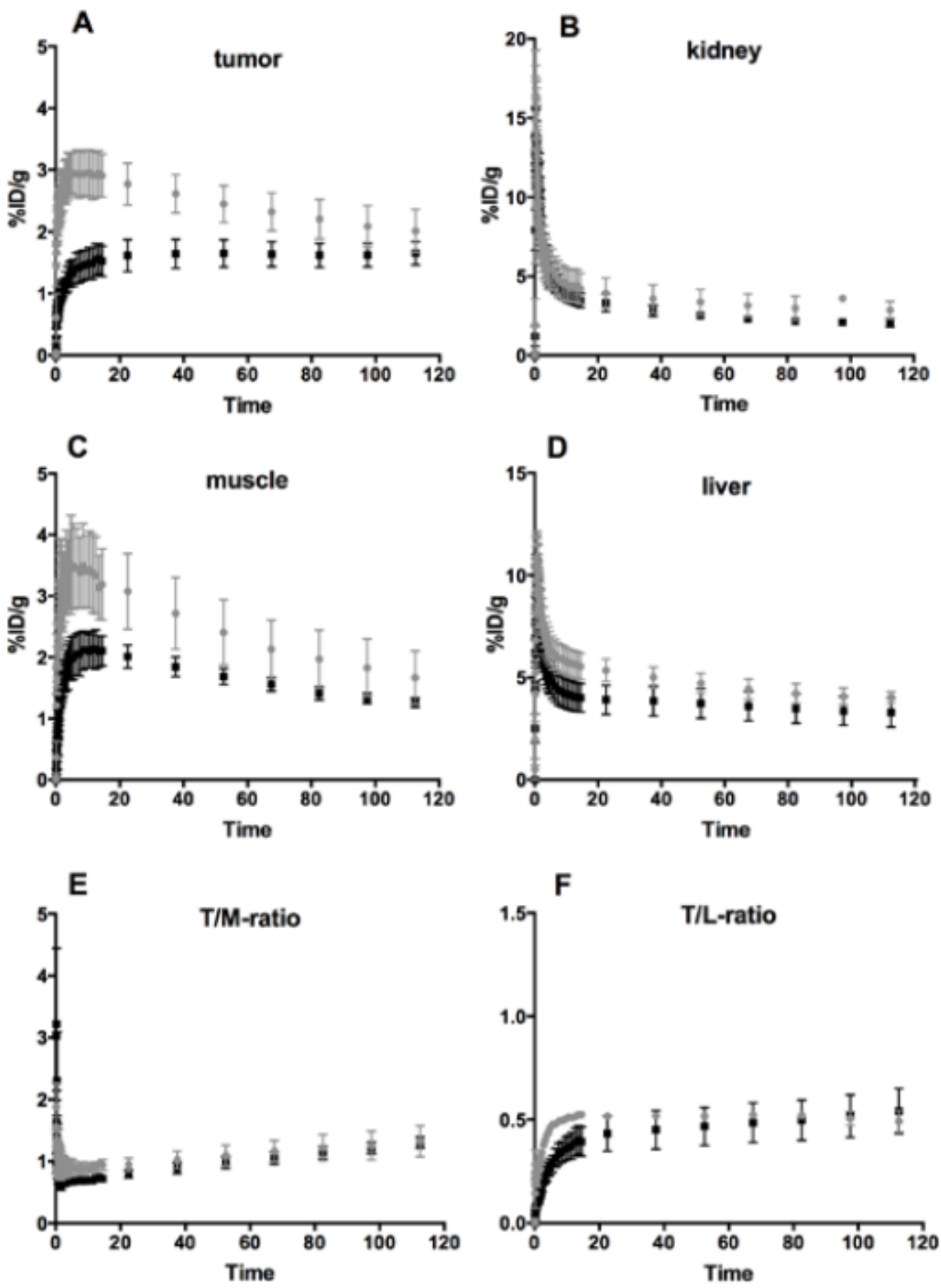

Fig. 6. Time activity curves from tumor-bearing mice obtained from $2 \mathrm{~h}$ dynamic PET scans showing the accumulation (mean $\pm S D$ ) of radioactivity over time in (A) tumor, (B) liver, (C) muscle, and (D) kidney; as well as (E) tumor-to-liver ratio and (F) tumor-to-muscle ratio. The PET acquisition was started a few seconds before intravenous injection of either $(\mathrm{R})-\left[{ }^{18} \mathrm{~F}\right] \mathrm{FMISO}(7.7 \pm 1.4 \mathrm{MBq}($ mean $\pm \mathrm{SD}) ; \mathrm{n}=3)$ or $(\mathrm{S})$ $\left[{ }^{18} \mathrm{~F}\right] \mathrm{FMISO}(8.8 \pm 1.8 \mathrm{MBq} ; \mathrm{n}=3)$. All animals were anesthetized during the scan by breathing $3 \%$ of 
sevoflurane dissolved in a gas mixture of 35\% oxygen in nitrogen. Except for tumor-to-muscle and tumor-to-liver ratios, results are expressed as \%ID/g. 